\title{
Parameters that Affect the Color of Direct Restorative Resins
}

John M. Powers, Joseph B. Dennison, and Patrick J. Luepeak

School of Dentistry, The University of Michigan, Ann Arbor, Michigan 48109, USA

The effects of thickness, background color, specular reflection, and surface roughness on the color of five commercial restorative resins were studied by reflection spectrophotometry. As thickness increased, values of luminous reflectance and excitation purity increased for a black background but decreased for a white background. Opacity increased dramatically as thickness increased from 1.3 to $3.9 \mathrm{~mm}$.

\section{J Dent Res 57(9-10):876-880, Sept.-Oct. 1978}

The color and opacity of commercial composite and unfilled direct restorative resins have been evaluated before and after accelerated aging to characterize the ability of these resins to match the color of human teeth. ${ }^{1,2}$ Additional factors that influence the shade of a

Received for publication December 28, 1977.

Accepted for publication February 23, 1978.

This investigation was supported in part by Research Grant DE-04136 and by Biomedical Research Support Grant RR-05321 from the National Institute of Dental Research, National Institutes of Health, Bethesda, Maryland 20014.

- Blak-Ray, Model B-100A, Ultra-Violet Products, Inc., San Gabriel, Ca 91775. restoration include the thickness, specular reflection, and roughness of the restoration and the color of the background whether it be tooth structure or the oral cavity. The purpose of this research was to evaluate the effect of the aforementioned variables on the color and opacity of certain composite and unfilled resins.

\section{Materials and Methods}

Four commercial composite resins and an unfilled restorative resin were studied. Codes, shades, batch numbers, and manufacturers of the materials are listed in Table 1.

Three sample disks $(36 \mathrm{~mm}$ in diameter and $1.3 \mathrm{~mm}$ in thickness) were made for each product by polymerizing the resin in a metal die. The samples were placed in an oven at $37 \mathrm{C}$ within 90 seconds after initiating the mix and were stored for 24 hours before testing. Specimens of the material (NF) activated by ultraviolet light were polymerized in the die by exposing the open side through a thin glass plate to an ultraviolet light source* for 2

\section{TABLE 1}

Codes, Products, Batch Numbers and Manufacturers of Restorative Resins Tested

\begin{tabular}{|c|c|c|c|}
\hline Code & Product & Batch Number & Manufacturer \\
\hline C & $\begin{array}{l}\text { Concise } \\
\text { (Universal) }\end{array}$ & $\begin{array}{r}\text { base-7080 E12 } \\
\text { catalyst-7080 E12 }\end{array}$ & $\begin{array}{l}\text { 3M Cio. } \\
\text { St. Paul, Mn } 55101\end{array}$ \\
\hline $\mathrm{NF}$ & $\begin{array}{l}\text { Nuva Fil } \\
\text { (Light) }\end{array}$ & $\begin{array}{r}\text { base- } 052877 \\
\text { catalyst }-120276\end{array}$ & $\begin{array}{l}\text { L. D. Caulk Co. } \\
\text { Div. of Dentsply } \\
\text { International, Inc. } \\
\text { Milford, De } 19963\end{array}$ \\
\hline $\mathbf{P}$ & $\begin{array}{l}\text { Prestige } \\
\text { (Universal) }\end{array}$ & $\begin{array}{r}\text { base-MS0015 } \\
\text { catalyst-MS0021 }\end{array}$ & $\begin{array}{l}\text { Lee Pharmaceuticals } \\
\text { South El Monte, Ca } 91733\end{array}$ \\
\hline SV & $\begin{array}{l}\text { Sevriton } \\
\text { (S5-Light Yellow) }\end{array}$ & $\begin{array}{l}\text { liquid-SG29SK } \\
\text { powder-PH26PH }\end{array}$ & $\begin{array}{l}\text { Amalgamated Dental Trade } \\
\text { Dist., Ltd. } \\
\text { London, England }\end{array}$ \\
\hline V & $\begin{array}{l}\text { Vytol } \\
\text { (Light) }\end{array}$ & $\begin{array}{r}\text { base }-042077 \\
\text { catalyst-050477 }\end{array}$ & L. D. Caulk Co. \\
\hline
\end{tabular}


minutes at a distance of $5 \mathrm{~cm}$. The arithmetic average roughness of a sample as measured from profile tracings $\dagger$ was $2.5 \mu \mathrm{m}$ for the rough side and $0.6 \mu \mathrm{m}$ for the smooth side.

Three samples at each of two additional thicknesses were obtained by placing any two of the $1.3-\mathrm{mm}$ samples $(a, b$, or $c)$ together to form 2.6-mm samples (i.e., ab, bc, and ca) and by placing all three of the $1.3-\mathrm{mm}$ samples together to form 3.9-mm samples (i.e., abc, bca, and cab).

Curves of percent reflectance versus wavelength $(\lambda)$ were obtained for three replications of each thickness $(1.3,2.6$, and $3.9 \mathrm{~mm}$ ) for each resin between 405 and $700 \mathrm{~nm}$ with a

† Surfanalyzer 150, Gould Inc., Instrument Systems Division, Cleveland, Oh 44114.

+ ACTA C III UV-Visible Spectrophotometer, Beckman Instruments, Inc., Irvine, $\mathrm{Ca} 92664$.

\$ ASPH-U Integrating Sphere, Beckman Instruments, Inc., Irvine, $\mathrm{Ca} 92664$.

I Part No 375287, Beckman Instruments, Inc., Irvine, $\mathrm{Ca} 92664$.

\# Part No. 104384, Beckman Instruments, Inc., Irvine, $\mathrm{Ca} 92664$.

* International Commission on Illumination.

t The computer program is available on request from the authors. double-beam, ultraviolet-visible spectrophotometer $\$$ and integrating sphere. $\S$ Each specimen (rough side) was evaluated in the sample port (25 $\mathrm{mm}$ in diameter) under two conditions for combined specular and diffuse reflectance: (1) backed by a black standardf and (2) backed by a white standard.\# A second white standard was used in the reference port for calibration of zero and $100 \%$ reflectance and to obtain data. Tristimulus values $(X, Y, Z$ ) relative to the $1931 \mathrm{CIE}^{*}$ color-matching functions for CIE standard illuminant $C$ were determined by numerical integration $(\Delta \lambda=$ $5 \mathrm{~nm}$ ) as described elsewhere. ${ }^{3}$ Values of CIE chromaticity coordinates $(x, y)$ were calculated from the tristimulus values ${ }^{3}$ and were used to obtain dominant wavelength and excitation purity from CIE chromaticity data $(1931)^{3}$ with the use of a computer program. $\mathrm{Lu}$ minous reflectance was equal to the tristimulus value, Y. An estimate of the opacity of each resin at each thickness was obtained by calculation of the contrast ratio, ${ }^{4} \mathrm{Y}$ black $/ \mathrm{Y}$ white.
Fig 1.-Luminous reflecance versus thickness for black and white backgrounds. Note that the data points at $3.9 \mathrm{~mm}$ also serve as the key.

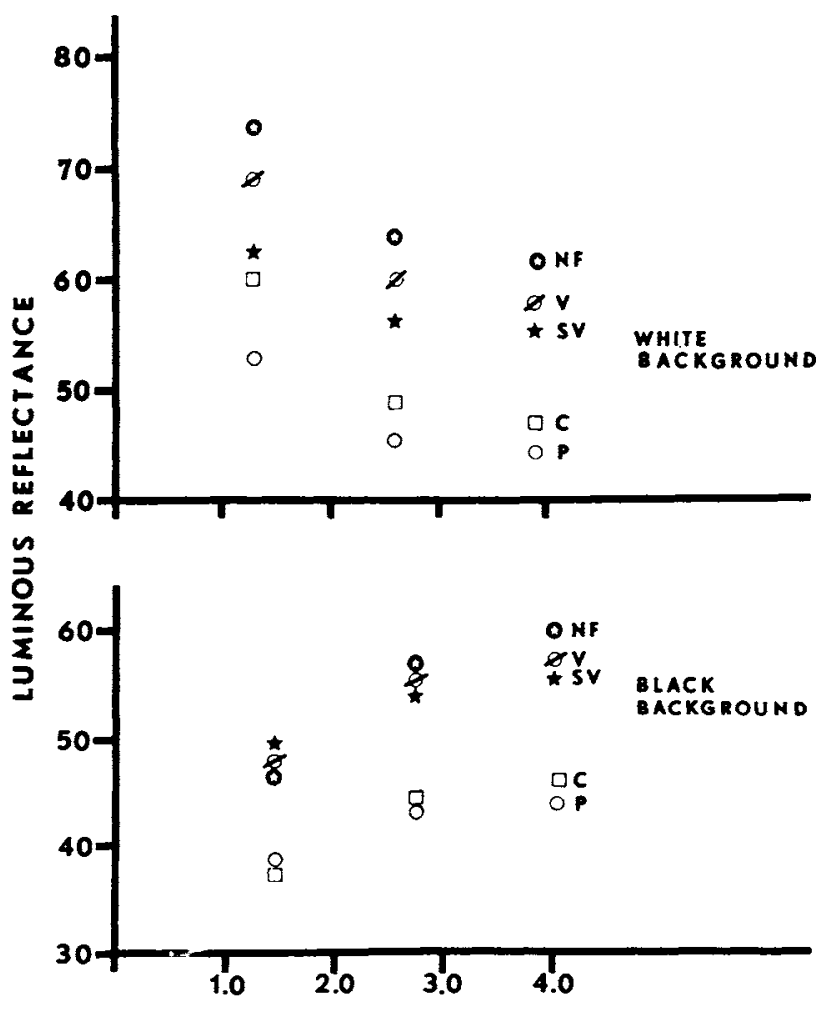

THICKNESS, mm 


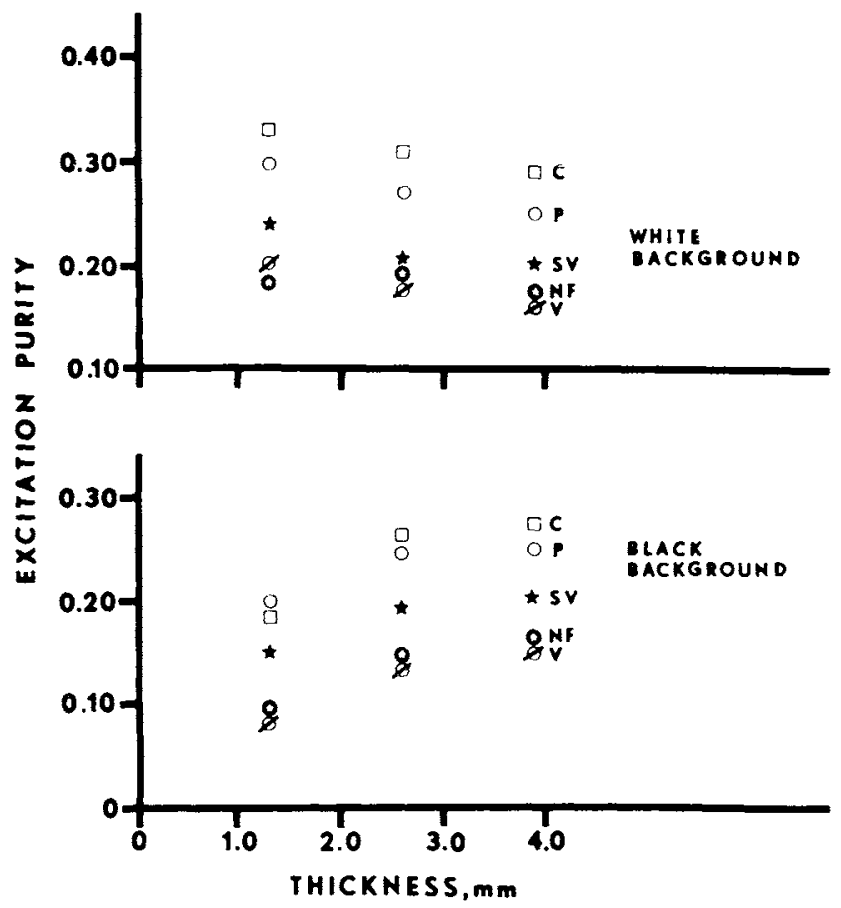

FIG 2.-Excitation purity versus thickness for black and white backgrounds. Note that the data points at $3.9 \mathrm{~mm}$ also serve as the key.
The spectrophotometric parameters, luminous reflectance, dominant wavelength, and excitation purity, were studied by a three-way analysis of variance ${ }^{5}$ to determine the effects of products, thickness and background conditions $[(i)$ and (ii)] for the resins. Data for the contrast ratio were studied by a two-way analysis of variance. ${ }^{5}$ Tukey's intervals at the $95 \%$ level of confidence were calculated ${ }^{6}$ for comparisons among means.

\section{Results}

The effects of thickness and background on the luminous reflectance and excitation purity of the direct restorative resins are shown in Figures 1 and 2, respectively. Differences among products, among thicknesses, and between backgrounds were statistically significant at the $95 \%$ level for both luminous reflectance and excitation purity. Tukey's intervals for comparisons among means are listed in Table 2. Significant differences in these variables also were observed for dominant wavelength, but the changes were too minor to justify presentation.

The effect of thickness on the contrast ratio of the direct restorative resins is shown in Figure 3. There were significant differences among the products and among the thicknesses at the 95\% level. Tukey's intervals for comparisons among means are listed in Table 2.

Spectrophotometric data for material $\mathrm{V}$ are listed in Table 3 to compare rough and smooth surfaces under conditions of combined specular and diffuse reflectance and diffuse reflectance only. The data were obtained for $1.3-\mathrm{mm}$ specimens with a white background. Significant differences were observed in the data for luminous reflectance and excitation purity, but not for dominant wavelength or contrast ratio at the $95 \%$ level. Tukey's intervals for comparisons among means were 0.6

\section{TABLE 2}

Tukey's Intervals for Gomparison Among Mean Val,ues of Spectrophotometric Data

\begin{tabular}{|c|c|c|c|c|}
\hline Comparisons & $\begin{array}{l}\text { Luminous } \\
\text { Reflectance }\end{array}$ & $\begin{array}{l}\text { Dominar } \\
\text { Wave- } \\
\text { length, } \\
\text { e nm }\end{array}$ & $\begin{array}{l}\text { Excitation } \\
\text { Purity }\end{array}$ & $\begin{array}{c}\text { Contrast } \\
\text { Ratio }\end{array}$ \\
\hline \multicolumn{5}{|l|}{ Among } \\
\hline Products & 0.9 & 0.31 & 0.005 & 0.014 \\
\hline \multicolumn{5}{|l|}{ Among } \\
\hline Thicknesses & 0.6 & 0.21 & 0.003 & 0.009 \\
\hline \multicolumn{5}{|l|}{ Between } \\
\hline Backgrounds & 0.4 & 0.14 & 0.002 & $\ldots . .$. \\
\hline
\end{tabular}


TABLE 3

Spegtrophotometric Data for Material V (1.3 mm Thigk) for Rough and Smooth Surfages With and Without Specular Reflection

\begin{tabular}{|c|c|c|c|c|c|}
\hline \multirow[b]{2}{*}{$\begin{array}{l}\text { Surface } \\
\text { Finish }\end{array}$} & \multirow[b]{2}{*}{$\begin{array}{c}\text { Type of } \\
\text { Reflectance }\end{array}$} & \multicolumn{4}{|c|}{ Spectrophotometric Parameter* } \\
\hline & & $\begin{array}{c}\text { Luminous } \\
\text { Reflectance }\end{array}$ & $\begin{array}{l}\text { Dominant } \\
\text { Wavelength, nm }\end{array}$ & $\begin{array}{c}\text { Excitation } \\
\text { Purity }\end{array}$ & $\begin{array}{c}\text { Contrast } \\
\text { Ratio }\end{array}$ \\
\hline \multirow[t]{2}{*}{ Rough } & $\begin{array}{l}\text { Diffuse } \\
\text { Diffuse and }\end{array}$ & $67.9(0.7) \dagger$ & $576.24(0.21)$ & $0.198(0.003)$ & $0.687(0.011)$ \\
\hline & Specular & $67.9(0.7)$ & $576.26(0.18)$ & $0.199(0.003)$ & $0.686(0.011)$ \\
\hline \multirow[t]{2}{*}{ Smooth } & Diffuse & $64.3(0.7)$ & $576.18(0.14)$ & $0.210(0.008)$ & $0.668(0.012)$ \\
\hline & $\begin{array}{l}\text { Diftuse and } \\
\text { Specular }\end{array}$ & $68.6(0.6)$ & $576.19(0.15)$ & $0.193(0.006)$ & $0.689(0.009)$ \\
\hline
\end{tabular}

* Obtained for a white background for $1.3 \mathrm{~mm}$ specimens.

$\uparrow$ Mean value of three replications with standard deviation in parentheses.

for luminous reflectance and 0.004 for excitation purity as calculated by a two-way analysis of variance.

\section{Discussion}

The clinical effect of increasing the thickness of the direct restorative resins studied from 1.3 to $3.9 \mathrm{~mm}$ is to increase dramatically the opacity of the resin as measured by the contrast ratio. The effect of increasing thickness on color depends on the color of the background. For a white background as might be represented by human enamel, an increase in thickness of resin resulted in decreasing values of luminous reflectance and excitation purity. Clinically, the resin might appear darker and less chromatic as thickness increases. For a black background as might be represented by the oral cavity, an increasing thickness of resin resulted in increasing values of luminous reflectance and excitation purity. Clinically, the resin might appear lighter and more chromatic as thickness increases. As the thickness of each resin increased, the contrast ratio approached one. Further, the color of each resin appeared to approach limiting values of luminous reflectance, dominant wavelength, and excitation purity independent of the black or white background as shown in Figures 1 and 2. Mean values of the spectrophotometric parameters of the resins studied for the $3.9-\mathrm{mm}$ thickness are listed in Table 4 for black and white backgrounds.

The specular component of reflected light had no effect on the spectrophotometric parameters when measured on a rough surface of material $\mathrm{V}$, but did result in an increased value of luminous reflectance and decreased value of excitation purity for a smooth surface compared to diffuse reflectance only. Glinically, a smooth surface will appear lighter and less chromatic under conditions of specular and

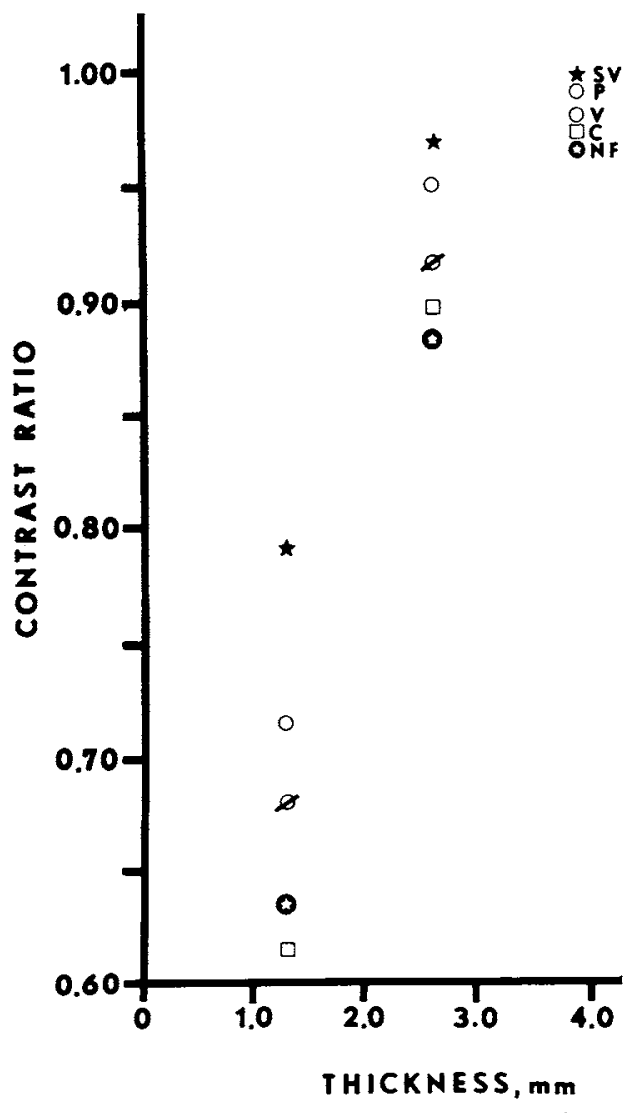

FIG 3.-Contrast ratio versus thickness. Note that the data points at $3.9 \mathrm{~mm}$ also serve as the key. 
TABLE 4

Spectrophotometric Parameters of Five Direct Restorative Resins For Black ANd White Bagkgrounds for a Thickness of 3.9 Mm

\begin{tabular}{ccccc}
\hline & & \multicolumn{3}{c}{ Spectrophotometric Parameter* } \\
\cline { 3 - 5 } Material & Background & $\begin{array}{c}\text { Luminous } \\
\text { Reflectance }\end{array}$ & $\begin{array}{c}\text { Dominant } \\
\text { Wavelength, um }\end{array}$ & $\begin{array}{c}\text { Excitation } \\
\text { Purity }\end{array}$ \\
\hline G & Black & $45.6(0.5)$ & $\mathbf{5 7 8 . 7 8 ( 0 . 0 2 )}$ & $0.273(0.003)$ \\
& White & $46.9(0.5)$ & $579.55(0.03)$ & $0.289(0.002)$ \\
NF & Black & $59.6(1.6)$ & $576.61(0.07)$ & $0.157(0.005)$ \\
& White & $61.7(1.7)$ & $577.55(0.01)$ & $0.176(0.005)$ \\
P & Black & $43.8(1.4)$ & $577.89(0.34)$ & $0.246(0.007)$ \\
& White & $44.3(1.3)$ & $578.04(0.05)$ & $0.250(0.008)$ \\
SV & Black & $\mathbf{5 5 . 2 ( 0 . 6 )}$ & $575.23(0.05)$ & $0.197(0.007)$ \\
& White & $55.4(0.6)$ & $575.57(0.04)$ & $0.199(0.007)$ \\
V & Black & $56.8(0.4)$ & $576.30(0.06)$ & $0.154(0.001)$ \\
& White & $57.9(0.4)$ & $577.12(0.07)$ & $0.166(0.001)$ \\
\hline
\end{tabular}

* Mean values of three replications with standard deviations in parentheses. For comparisons among means, refer to Tukey's intervals in Table 2.

diffuse reflectance compared to diffuse reflectance only. Under conditions of diffuse reflectance, a rough surface would appear lighter and less chromatic than a smooth surface.

\section{Conclusions}

The effects of thickness, background color, specular reflection, and surface roughness on the color of five commercial composite and unfilled direct restorative resins were studied by reflection spectrophotometry. As thickness increased from 1.3 to $3.9 \mathrm{~mm}$, values of luminous reflectance and excitation purity increased for a black background but decreased for a white background. Opacity increased dramatically as thickness increased. The specular component of reflected light resulted in increased luminous reflectance and decreased excitation purity compared to diffuse reflectance for a smooth surface. Under conditions of diffuse reflectance, a rough surface had increased luminous reflectance but decreased excitation purity compared to a smooth surface.
The cooperation of the following companies in providing commercial products is acknowledged: L. D. Caulk Co, Lee Pharmaceuticals, and the 3M Company.

\section{References}

1. Dennison, J.B.; Powers, J.M.; and Koran, ANDREW: Color of Dental Restorative Resins, $J$ Dent Res (In Press).

2. Powers, J.M.: Dennison, J.B.; and Koran, Andrew: Color Stability of Restorative Resins Under Accelerated Aging, J Dent Res, in press.

3. Wyszecki, G., and Stiles, W.S.: Color Science, New York, Wiley and Sons, Inc., 1967, $628 \mathrm{pp}$.

4. Opacity of Paper, D589-65 (1970): (in ASTM Standards, 1975, part 20. Philadelphia, American Society for Testing Materials, 1975, pp. 86-88.

5. DALBY, JoH, programmer: BMD8V-Analysis of Variance, Ann Arbor, Statistical Research Laboratory, University of Michigan, 1968, 4 pp.

6. Guenther, W.C.: Analysis of Variance, Englewood Cliffs, NJ, Prentice-Hall, 1964, $199 \mathrm{pp}$. 